Revista Chilena
De Pediatría

www.revistachilenadepediatria.cl

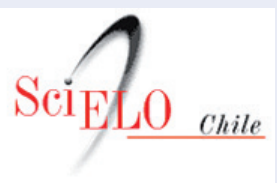

www.scielo.cl

\title{
Orientaciones Deporte y COVID-19: Recomendaciones sobre el retorno a la actividad física y deportes de niños niñas y adolescentes
}

\author{
Sport COVID-19 Orientations: Recommendations for return to physical activity and \\ sports in children and adolescents
}

\author{
César Kalazich Rosales ${ }^{\mathrm{a}}$, Paulo Valderrama Erazo ${ }^{\mathrm{b}}$, Jorge Flández Valderrama ${ }^{c}$, \\ Jair Burboa González ${ }^{\mathrm{d}}$, Daniel Humeres Terneus ${ }^{\mathrm{e}}$, Raúl Urbina Stagnof, \\ Francisca Jesam Sarquis ${ }^{\text {g }}$, Andrés Serrano Reyes ${ }^{\text {h }}$, Francisco Verdugo Miranda ${ }^{\mathrm{i}}$, \\ Raúl Smith Plaza', Luis Valenzuela Contreras ${ }^{\mathrm{k}}$
}

\begin{abstract}
aMédico del Deporte, Fútbol Formativo CDUC-Cruzados, Selecciones Nacionales Juveniles Masculinas y Femeninas de Fútbol. Clínica MEDS. Red Salud UC-Christus. Presidente Sociedad Chilena de Medicina del Deporte (SOCHMEDEP). Chile

bPediatra, Cardiólogo Pediatra. Pontificia Universidad Católica de Chile. Presidente del Comité de Medicina del Deporte y la Actividad Física, Sociedad Chilena de Pediatría (SOCHIPE). Chile

cProfesor de Educación Física, Director Carrera Educación Física Universidad Austral de Chile. Consejo Académico Nacional de Educación Física (CANEF). Chile

¿Kinesiólogo, Selecciones Nacionales Juveniles Masculinas y Femeninas de Fútbol, Centro Medicina Deportiva Clínica Santa María. Universidad Metropolitana de Ciencias de la Educación. Sociedad Chilena de Kinesiología del Deporte (SOKIDE). Chile eMédico del Deporte, Área Médica Fútbol Joven CSD Colo-Colo. Clínica MEDS. Unidad de Ejercicio y Deporte Adaptado Teletón Chile. Sociedad Chilena de Medicina del Deporte (SOCHMEDEP). Chile

fProfesor de Educación Física. Kinesiólogo. Universidad Andrés Bello. Universidad de Los Andes. Comité de Medicina del Deporte y la Actividad Física, Sociedad Chilena de Pediatría (SOCHIPE) y Asociación de Profesores de Educación Física. Chile

9Kinesióloga, Selecciones Nacionales Juveniles Masculinas y Femeninas de Fútbol. Sociedad Chilena de Kinesiología del Deporte (SOKIDE).

Chile

hMédico del deporte, Área Médica Fútbol Formativo CDUC-Cruzados. Unidad Médica CDUC-Red Salud UC-Christus. Instructor adjunto Pontificia Universidad Católica de Chile. Sociedad Chilena de Medicina del Deporte (SOCHMEDEP). Chile Pediatra y Médico del Deporte. Universidad Mayor. Comité de Medicina del Deporte y la Actividad Física, Sociedad Chilena de Pediatría (SOCHIPE) y Sociedad Chilena de Medicina del Deporte (SOCHMEDEP). Chile

¡Médico del Deporte y Fisiatra. Universidad del Desarrollo. Unidad de Ejercicio y Deporte Adaptado Teletón Chile. Hospital Clínico Mutual de Seguridad C.Ch.C. Clínica Alemana. Sociedad Chilena de Medicina del Deporte (SOCHMEDEP). Chile

kProfesor de Educación Física. Decano de la Facultad de Educación Universidad Católica Silva Henríquez. Chile
\end{abstract}

Recibido: 24 de junio de 2020, Aceptado para publicación el 9 de julio de 2020

Correspondencia:

Francisco Verdugo Miranda

franciscoverdugo@gmail.com 


\section{Resumen}

La pandemia por COVID-19, originada en diciembre de 2019 en Wuhan, China, obligó a los países, incluido Chile, a un confinamiento masivo para evitar la propagación de SARS-CoV2. Desde marzo de 2020 en Chile, también se afectó la realización de actividad física y deporte en los niños, niñas y adolescentes (NNA). En un esfuerzo por reunir la escasa evidencia disponible sobre el retorno a la práctica de ejercicio en NNA post pandemia COVID-19 y la opinión de expertos de 4 sociedades científicas y académicas (Sociedad Chilena de Medicina del Deporte, Sociedad Chilena de Pediatría, Sociedad Chilena de Kinesiología Deportiva y la Consejo Académico Nacional de Educación Física) se han generado recomendaciones para un retorno seguro a la actividad para el ramo Educación Física y Salud, deporte escolar y federado tanto para disminuir los riesgos asociados a los efectos del confinamiento como para evitar la propagación de COVID-19. Adicionalmente, se incluyen una guía de recomendación para padres y profesores y otra para médicos sobre la vigilancia y evaluación de los pacientes NNA que sostendrán enfermedad COVID-19 y deseen volver al deporte y ejercicio.

\section{Abstract}

The COVID-19 pandemic, originated in December 2019 in Wuhan, China, forced a massive quarantine in most countries including Chile to avoid the propagation of SARS-CoV2. Since March 2020 in Chile, it affected the participation of children and youth athletes as well in education, physical activity and sports. In an effort to assess the scarce available evidence about return to sport and exercise in children and adolescents post COVID-19 pandemic and gather the opinion of experts of 4 Chilean scientific and academic societies (Sociedad Chilena de Medicina del Deporte, Sociedad Chilena de Pediatría, Sociedad Chilena de Kinesiología Deportiva and Consejo Académico Nacional de Educación Física) we have produced recommendations for a safe return to activities in Physical Activity and Health class, School Sports and Federation Sports to reduce the risks associated with the effects of confinement and to avoid the propagation of COVID-19 and. Additionally, a recommendation for parents and teachers and a another for physicians for surveillance and evaluation of children and adolescents who were or will become COVID-19 patients and wish to return to sports end exercise.

\section{Palabras clave:}

Ejercicio;

Deportes;

Atleta;

COVID-19;

Pandemia;

Reanudación de

Actividades Deportivas;

Regreso al

Entrenamiento;

Convalecencia

Keywords:

Exercise;

Sports;

Athlete;

COVID-19;

Pandemic;

Resumption of

Sporting Activities;

Return to Training;

Convalescence

\section{Parte I: Conceptos generales, condiciones actuales y del retorno}

\section{Antecedentes generales (causa de confinamiento, consecuencias en la salud, la condición física y el rendimiento deportivo)}

A fines de diciembre del 2019, el gobierno chino informó de casos de síndrome respiratorio agudo severo (SARS, por sus siglas en inglés) provocado por un nuevo coronavirus, SARS-CoV-2 en Wuhan, China. La enfermedad se denominó COVID-19, que demostró gran capacidad de contagio, propagándose rápidamente al resto del mundo, informándose el primer caso fuera de Wuhan (Tailandia) el 13 de enero y declarándose emergencia mundial el 30 de enero de 2020 por la Organización Mundial de la Salud (OMS). El 26 de febrero se informa el primer caso en Brasil y finalmente el 3 de marzo el primer caso en Chile, de un paciente proveniente de Singapur. La forma de presentación de COVID-19 varía desde absolutamente asintomático, síntomas similares a una gripe, con fiebre, síntomas respiratorios leves, síntomas digestivos, pérdida del olfato y gusto, hasta una neumonía con distress respiratorio agudo severo ${ }^{1}$.
La OMS recomienda el confinamiento o cuarentena como la medida más eficaz para contener la propagación del virus, basado en experiencias con SARSCoV y MERS y en la actual contención de China y otros países para COVID-19. En este contexto, el Ministerio de Salud de Chile, mediante Resolución Exenta $\mathrm{N}^{\circ} 200$, de 20 de marzo del presente, dispuso una serie de medidas por el brote del virus SARS-CoV2, entre otras, la suspensión de los eventos deportivos profesionales, amateur y actividad física (AF) recreativa, a contar de las 00:00 horas del 21 de marzo, y de forma indefinida, hasta que las condiciones epidemiológicas permitan la supresión de esta medida. Además se instauraron cuarentenas en las principales ciudades del país, impidiendo salir de la casa y por lo tanto limitando la AF al aire libre ${ }^{2}$.

El confinamiento genera una serie de problemas a la salud, tanto físicos como psicológicos. La inactividad física es uno de los principales problemas de salud en la actualidad y el confinamiento profundiza aun más los riesgos que conlleva como problemas de salud cardiovascular, obesidad, depresión, varios tipos de cáncer, etc ${ }^{3}$. La actividad física para mantener y mejorar la salud debe ser visto como una política pública no sólo 
para niños, niñas y adolescentes sino que para la población general y debe ser abarcado desde una perpectiva integral (educacional, sanitaria, laboral, de transporte, etc.) tanto en confinamiento como una vez que se retorne a las posibilidades relativamente normales de realizar de AF, ejercicio y deporte ${ }^{4}$.

Cómo es de esperar, los deportistas no están exentos a estos problemas, incluido un potencial detrimento significativo de su rendimiento. Mujika y Padilla (Sports Med. 2000) ${ }^{5}$ nos describen una serie de consecuencias del desentrenamiento sobre las 4 semanas en los ámbitos cardiorrespiratorio, metabólico, hormonal y muscular.

\section{Consecuencias cardiorrespiratorias}

La capacidad aeróbica (según VO2max) puede disminuir entre un 6 y un $20 \%$ para estabilizarse. El volumen total de sangre y plasma disminuye un 4 y $3 \%$, respectivamente. La frecuencia cardíaca de reposo aumenta un 5\% luego de 84 días sin entrenamiento. En atletas que entrenan regularmente el volumen sistólico puede disminuir entre un 14 y un $17 \%$ después de 2 a 3 meses de desentrenamiento. El volumen ventilatorio disminuye entre un 10 y un 14\%. El tiempo a la fatiga disminuye hasta en un 24\% luego de 5 semanas sin entrenamiento en futbolistas.

\section{Consecuencias metabólicas}

Aumenta la utilización de carbohidratos; potencial aumento de la insulina, glucosa basal y triglicéridos (Martínez y cols. Nutrients.2020). Además disminuye lipólisis; aumenta el umbral de lactato y disminuye el glicógeno muscular.

\section{Consecuencias hormonales}

Ineficiente respuesta catecolaminas en ejercicio submáximo (Coyle y cols.J Appl Phys.1985)

\section{Consecuencias musculares}

La actividad enzimática mitocondrial puede disminuir entre un $25-40 \%$ principalmente en fibras lentas, manteniéndose en fibras rápidas, de modo que, es probable que, la producción de ATP disminuya significativamente. Reducción del área seccional de grupos musculares principales, reducciones específicas de fibras rápidas con aumento de las fibras lentas de atletas de fuerza. Disminución de la masa muscular.

\section{Reducción de entrenamiento}

A diferencia de la suspensión total del entrenamiento, su reducción logra disminuir o aplazar los cambios fisiológicos descritos, sin embargo, esta situación no tiene precedentes en la historia por lo que es una oportunidad para la ciencia para descubrir las alteraciones fisiológicas y en salud.
En un estudio observacional sudafricano en 692 atletas de varias disciplinas, $61 \%$ entrenaban sólos, la mayoría a moderada intensidad y durante 30 a 60 minutos. Los atletas preferían un comportamiento sedentario durante su tiempo de ocio. Muchos cambiaron sus hábitos de sueño (79\%); muchos se sintieron deprimidos y requerían motivación para entrenar. Un número significativo de atletas han estado comiendo carbohidratos en exceso (73\% los hombres; $80 \%$ las mujeres) $)^{6}$.

\section{Prevención de lesiones músculoesqueleticas en el retorno al deporte}

No existen precedentes al confinamiento vivido por el COVID-19, el antecedente más similar reportado fue el cierre temporal que tuvo la liga de fútbol americano (NFL) el 2011, en el cual los deportistas no tenían acceso a las instalaciones deportivas o profesionales de las diferentes áreas durante 19 semanas. Una vez volvieron a la actividad, tuvieron una rápida transición desde que retomaron los entrenamiento al inicio de la competencia en 17 días.

Debido al poco tiempo de entrenamiento y preparación para la competencia, en tan solo las primeras dos semanas de retorno al entrenamiento, 10 deportistas sufrieron la ruptura de sus tendones aquilianos, lo cual fue sorprendente ya que en estadísticas de años anteriores habían reportadas 5 rupturas durante todo el año ${ }^{7}$.

Según lo señalado, proponemos un manejo y control de cargas de entrenamiento individualizado para cada deportista; la planificación y progresión de ejercicios, volumen, intensidad y movimientos propios del deporte practicado, ya que estos factores se han visto modificados debido al entrenamiento en confinamiento, limitación del espacio y modificación en rutinas de entrenamiento.

Se deben respetar los tiempos de adaptación a la actividad deportiva y asegurar una óptima recuperación posterior a los estímulos. Se recomienda realizar ejercicios preventivos de carácter excéntricos y control de zona media a lo largo de las diferentes fases de la pandemia.

Es importante conocer el entrenamiento efectivamente realizado por el NNA en confinamiento, para no generar cambios bruscos en su carga aguda de entrenamiento. Si esto no es bien controlado, aumenta considerablemente la posibilidad de lesionarse.

El tiempo de re-acondicionamiento depende del estado físico del deportista (o NNA). El re- entrenamiento junto con la preparación para la competición debe ser de al menos 30 días. En el caso de que el deportista haya estado inactivo por un tiempo prolongado y sus capacidades físicas están deterioradas, el tiempo necesario para volver a estar en óptima forma física y condiciones para competir es aún mayor. 
Al momento de que la pandemia por COVID-19 muestre una mejoría que permita a las autoridades sanitarias autorizar el retorno deportivo, se debe considerar una apropiada puesta a punto para cada deporte en específico, considerando estos tres elementos claves $^{7-10}$ :

- Posibles efectos de desacondicionamiento, que llevan a una modificación de las propiedades estructurales y biomecánicas de tejidos como ligamento, músculo y tendón.

- Cargas de entrenamientos después de períodos de inactividad y progresión de estas.

- De no mediar un cambio en el tipo de competencia, esta el riesgo de el aumento de densidad de encuentros, debido a la disminución de tiempos para finalizar campeonatos.

A modo de ejemplo, en la Bundesliga el promedio de lesiones por encuentro subió de 0,27 por encuentro antes del confinamiento a 0,58 por encuentro una vez que retornaron (hasta la $8 \mathrm{va}$ fecha post cuarentena), y no solo eso, también se percibe una leve disminución en la cantidad de sprints y en las distancias recorridas, por lo que estas lesiones se están produciendo a intensidades más bajas de las que se provocaron previo al confinamiento. Hasta el momento de la edición de este documento, se reportaba un comportamiento similar en las ligas españolas e inglesas de fútbol ${ }^{11}$.

\section{Utilización o no de mascarillas}

No existe evidencia robusta que el uso de mascarilla, mientras se realiza ejercicio físico, sea mejor que la distancia física para disminuir la propagación del virus.

La mascarilla trae una serie de desventajas fisiológicas y, por lo tanto, en el rendimiento deportivo, que si bien son menores puede dificultar un entrenamiento o competencia. Desde la disminución de la capacidad aeróbica subjetiva a una leve hipoxia e hipercapnea, que probablemente se logre adaptar y vuelve a la normalidad, sin embargo, los estudios en distintos deportes no se han realizado ${ }^{12}{ }^{13}$.

\section{Concepto de Distancia Deportiva}

Según estudios de simulación (Blocken y cols. 2020) en la propagación de gotas de peso específico en los cuales el coronavirus se desplaza, muestra que la distancia mínima en línea recta en condiciones climáticas ideales son 5 metros y a mayores velocidades es hasta 10 metros $(14,4 \mathrm{~km} / \mathrm{hr})$; acorde a esto, a mayor velocidad de desplazamiento se requerirá mayor distancia en linea recta entre los sujetos. Por lo tanto, se plantea que la distancia deportiva debe ser de al menos 5 metros en ejercicios moderados y 10 metros en ejercicios intensos de rápidos desplazamientos. Esta distancia debe contemplar el espacio, en todas las direcciones en que se desplaza el atleta ${ }^{214}$.

\section{Concepto de progresión en nivel de contacto físico, espacios}

La progresión de los entrenamientos contempla la dimensión de cantidades de atletas que comparten un espacio y el uso del espacio para recibir atletas. Conviene comenzar con entrenamiento individual, seguido por entrenamientos grupales de grupos pequeños en progresión (4-8-12 y más). Todo esto en progresiones semanales, de acuerdo a las realidades epidemiológicas y medidas sanitarias.

Los espacios ideales deberían ser una distancia mínima de 5 metros entre alumnos para ejercicios moderados y 10 metros para ejercicios intensos de rápidos desplazamientos. Si los espacios no son los suficientes para mantener la distancia deportiva, deberán entrenar en horarios diferentes para mantener los números de atletas o alumnos.

\section{Uso de espacios abiertos o cerrados}

Recomendamos no limitar la AF o deporte mediante los conceptos de espacios abiertos (patios, canchas) o cerrados (gimnasios) sino más bien atenerse a los conceptos de la distancia física y deportiva.

No existe evidencia científica que el virus SARSCoV2 se esparce en el agua. Sin embargo, la evidencia actualmente disponible tampoco nos permite asegurar que el uso de piscinas sea seguro. En el caso de elegir el uso de piscinas, éstas deben tener las condiciones de tamaño para lograr mantener la distancia física y deportiva en la piscina y fuera de ella (camarines, espacios comunes) ${ }^{15}$.

Adicionalmente, la adecuada mantención de piscinas y la desinfección del agua (soluciones cloradas) debería inactivar el virus ${ }^{15}$.

\section{Condiciones para el retorno y para la progresión desde el regreso al aula hasta las actividades deportivas extracurriculares ${ }^{17,18}$}

- Cuando la autoridad sanitaria decida que las clases se reanuden en forma presencial dentro del aula, deberá darse dos semanas de inducción para sentar las bases para la práctica de la Educación Física y Salud, reforzando las medidas sanitarias, de distanciamiento físicos y las conductas de niños, niñas y adolescentes (NNA), preparando la infraestructura y horarios de gimnasios, canchas y espacios destinados para ello.

- Considerar trabajos lineales, individuales (carriles) que mantengan la distancia deportiva.

- Es necesario considerar que las decisiones de entrada o progresión de la AF tanto en los establecimientos educacionales como en los recintos deportivos deben ser flexibles a la realidad epidemiológica local y las decisiones sanitarias de cada establecimiento. 
- $\quad$ En el caso de que un NNA haya sido o sea positivo para COVID-19 deberá tener una evaluación y posterior certificado médico para realizar AF y/o deporte competitivo (evaluación preparticipativa), según recomendaciones en 'Parte V'.

\section{Objetivos generales}

Orientar y recomendar estrategias para retomar la AF y deporte, sus beneficios para la salud biopsicosocial de los NNA, comunidad educacional y deportiva en condiciones sanitarias seguras para evitar contagios en el contexto de la pandemia de COVID-19 como un marco general que contemple las distintas realidades del país.

\section{Objetivos específicos}

Señalar los beneficios de la AF y el deporte en la población de NNA.

Mantener los hábitos de AF durante el confinamiento y, posterior a esto, en los establecimientos educacionales y recintos deportivos. De modo de mantener la condición física tanto de deportistas como de no deportistas.

Mantener y reforzar las medidas de higiene, distanciamiento físico y deportivo para que se cumplan en las casas y establecimientos educacionales de modo de evitar la propagación del virus en la población general y velar por la seguridad y salud de los NNA, profesores y sus familias.

Usar la AF como medio de educación en medidas sanitarias.

\section{Recomendaciones de Actividad Física en NNA (5-17 años $)^{18}$}

Para los niños y jóvenes de este grupo de edades, la actividad física consiste en juegos, deportes, desplazamientos, actividades recreativas, educación física o ejercicios programados, en el contexto de la familia, la escuela o las actividades comunitarias. Con el fin de mejorar las funciones cardiorrespiratorias y musculares y la salud ósea y de reducir el riesgo de Enfermedades Crónicas No Transmisibles (ECNT), la OMS recomienda que:

- Los niños y jóvenes de 5 a 17 años inviertan como mínimo 60 minutos diarios en actividades físicas de intensidad moderada a vigorosa.

- La actividad física por un tiempo superior a 60 minutos diarios reportará un beneficio aún mayor para la salud.

- La actividad física diaria debería ser, en su mayor parte, aeróbica. Convendría incorporar, como mínimo tres veces por semana, actividades vigorosas que refuercen, en particular, los músculos y huesos.
Estas recomendaciones son válidas para todos los niños sanos de 5 a 17 años, salvo que coincidan dolencias médicas específicas que aconsejen lo contrario.

Se habla de acumulación para referirse a la meta de dedicar en total 60 minutos diarios a realizar alguna actividad, incluida la opción de dedicar a distintas actividades intervalos más cortos (por ejemplo dos sesiones de 30 minutos) y sumar esos intervalos.

\section{Normas permanentes durante la pandemia ${ }^{2}$}

Las siguientes normas son las que la autoridad sanitaria ha difundido por todos los medios y otras que responden a evidencia científica disponible recientemente $y$, por lo tanto, deben ser respetadas por todos NNA, padres, tutores, profesores, administrativos, personal de aseo y otros en relación a establecimientos educacionales o instituciones deportivas:

- Lavado de manos frecuente (al inicio y término del entrenamiento, además al tener contacto con superficies o elementos posiblemente contaminados) por al menos 30 segundos con agua y jabón o usar alcohol gel. Se aconseja usar alcohol gel máximo 3 veces entre lavado de manos con agua y jabón.

- Evitar llevarse las manos a la cara (ojos, nariz, boca).

- Mantener "distancia física" mínima con otras personas ( 1,5 metros) en sus actividades cotidianas.

- Mantener distancia deportiva mínima de 5 metros con otras personas durante el ejercicio físico moderado (en el lugar y en trote, por ejemplo) y 10 metros para ejercicios de rápidos desplazamientos.

- Higiene respiratoria: en caso de tos o estornudo, hacerlo sobre el antebrazo o en pañuelo desechable, eliminando posteriormente en basurero tapado y realizar lavado de manos posteriormente.

- Limpiar superficies, en particular aquellas con alto uso, dado que el virus tiene un tiempo variable de supervivencia en ellas (para detalles de limpieza de superficies en lugares de trabajo, remítase al documento MINSAL: 'Protocolo de limpieza y desinfección de ambientes COVID-19’ '*.

- Durante las fases iniciales del retorno a la AF recomendamos no compartir implementos. Luego, cuando se permitan, dar tiempo para la limpieza de cada implemento (según Normas MINSAL) después de su uso (tabla 3 ).

- No compartir alimentos ni líquidos. Cada NNA debe llevar su propia botella llenas desde la casa.

- No tener contacto físico directo con personas ajenas al grupo familiar (que vivan en el mismo hogar), incluyendo el no realizar saludo de mano, beso y abrazo.

- Uso de mascarilla en lugares público, en población sana o asintomática acorde a las indicaciones del Ministerio de Salud. 
- En la situación de cuarentena esta debe respetarse de acuerdo con la normativa sanitaria. Cuando ésta no exista, se recomienda mantener un aislamiento físico personal y familiar razonable, evitando los contactos innecesarios que puedan contribuir al riesgo de adquirir la enfermedad.

- En caso de síntomas sugerentes de COVID-19, posibles contactos con caso sospechoso o confirmados de COVID 19, o cualquier duda, comunicarse con personal de salud de las instituciones educacionales, deportivas y/o representante legal para decidir la mejor conducta según protocolo sanitario vigente.

- Se enfatiza que el Programa Nacional de Inmunización esté al día acorde a la edad, incluyendo la vacunación contra influenza estacional.

\section{Concepto de Progresión o Desescalada en Fases $^{2,10,19,20}$}

Al igual que otros países y, cuando la realidad epidemiológica nacional y comunal lo permita, se comenzará un Plan de Desescalada o Progresión en fases. Conceptualmente las 'fases' sugeridas a la autoridad.

Fase 0: Cuarentena total de la comuna, medidas de distanciamiento e higiene.

Fase 1: Cuarentena parcial, apertura de negocios esenciales, transporte parcialmente funcional, cordones sanitarios.

Fase 2: Sin cuarentena, apertura de negocios esenciales, transporte parcialmente funcional, cordones sanitarios.

Fase 3: Sin cuarentena, apertura escalonada de negocios, transporte parcialmente funcional, sin cordones sanitarios.

Fase 4: Sin cuarentena, apertura completa de negocios, transporte parcialmente funcional, sin cordones sanitarios.

Fase 5: Sin restricciones, sólo medidas de higiene.

Si comunal o regionalmente, no existen las restricciones mencionadas se deberá progresar de fases cada 7 a 10 días según condiciones epidemiológicas y de infraestructura de cada establecimiento (tabla 1).

\section{Parte II: Retorno a la Educación física ${ }^{16,17}$}

La actual pandemia, generada por el SARS-CoV-2 y la situación socio sanitario inédita, compleja, desafiante y sin precedentes en la historia de nuestro país, ha obligado a diversos sectores y expresiones de la sociedad (público y privado) a realizar esfuerzos excepcionales, con el propósito de resguardar la seguridad y la salud de las y los ciudadanos. En este escenario, los colegios e instituciones de la Educación Superior en su conjunto, se han visto en la obligación de implementar acciones especiales para abordar de manera responsable la actual situación. En ese ámbito, se han generado diversas adecuaciones, re-adaptaciones de sus estructuras, protocolos como también, de sus formas habituales de aprendizaje, actuación y convivencia.

Al respecto, uno de los espacios significativos e importantes del mundo de la educación formal, es la Educación Física y salud, el deporte, la actividad física y ejercicio, que ocupan un lugar educativo relevante en el currículum y los proyectos educativos en general, expresados en las clases de carácter obligatorio, actividades extraescolares, talleres, academias, prácticas diversas del deporte escolar y universitario de carácter representativo, que de una forma, logran tributar a cada uno de los objetivos estratégicos de sus instituciones, con ventanas de oportunidades diversas y claves para la formación integral. Se suman a ello, otras manifestaciones importantes asociadas a la práctica de regular de actividad física y el ejercicio, con distintos sentidos y propósitos y al cual de adhieren distintos grupos etarios y género.

A la luz de lo anterior y de acuerdo a las actuales normativas sanitarias y ante un potencial tránsito de la crisis hacia una nueva realidad para la educación escolar y universitaria en el área de la Educación Física, salud, deporte y la recreación, se hace necesario garantizar aspectos preventivos específicos, de seguridad e higiene, que nos obligará a asumir nuevos retos, re direccionando la actual política educativa y deportiva en el sector, que requerirá pensarnos de manera distinta, instalando protocolos de actuación que consideren nuevos códigos de comunicación, ejecución y de relación, que al menos, permitan agenciar y garantizar de manera progresiva tanto el autocuidado como el co cuidado, y la continuidad de la formación curricular y deportiva.

En este particular escenario, lo descrito, está siendo un tema controversial en el país y en el mundo. Ante este ámbito, se presenta un anexo resumen que tiene como propósito aportar y proponer algunas recomendaciones básicas vinculadas al sector, para dar respuestas a algunas inquietudes propias en tiempos de pandemia y en consonancia con las actuales disposiciones sanitarias y a una realidad que al parecer cambiará constantemente. A continuación, independiente del enfoque, estructura y formas de plantear una sesión de trabajo, se recomienda tener presente las siguientes recomendaciones (tabla 2 ). 
Tabla 1. Fases de progresión general del deporte y la actividad física en NNA

\begin{tabular}{|c|c|c|c|c|c|c|c|}
\hline Nombre & $\begin{array}{l}\text { Nivel de } \\
\text { Riesgo }\end{array}$ & Descripción & $\begin{array}{c}\mathrm{AF} \\
\text { Domiciliaria }\end{array}$ & Clase Ed. Física & $\begin{array}{c}\text { Entrenamiento } \\
\text { Escolar }\end{array}$ & $\begin{array}{l}\text { Entrenamiento } \\
\text { Federado }\end{array}$ & AF Aire Libe \\
\hline Fase 0 & $\begin{array}{l}\text { Riesgo } \\
\text { Muy Alto }\end{array}$ & $\begin{array}{l}\text { Existe toque de queda } \\
\text { o restricciones obliga- } \\
\text { torias sobre el movi- } \\
\text { miento de personas }\end{array}$ & $\mathrm{Si}$ & $x$ & $x$ & $\begin{array}{l}\text { Entrenamiento } \\
\text { en domicilio } \\
\text { guiado por en- } \\
\text { trenadores según } \\
\text { Federación }\end{array}$ & $x$ \\
\hline Fase 1 & $\begin{array}{l}\text { Riesgo } \\
\text { Alto }\end{array}$ & $\begin{array}{l}\text { Existen restricciones de } \\
\text { circulación (diagnos- } \\
\text { ticados COVID }(+) \\
\text { activos o personas en } \\
\text { cuarentena preventiva) } \\
\text { y no existe toque de } \\
\text { queda }\end{array}$ & $\mathrm{Si}$ & $x$ & $x$ & $\begin{array}{l}\text { Cumpliendo pro- } \\
\text { tocolo general } \\
\text { y específico de } \\
\text { cada Federación } \\
\text { Y recomendacio- } \\
\text { nes sanitarias. }\end{array}$ & $x$ \\
\hline Fase 2 & $\begin{array}{c}\text { Riesgo } \\
\text { Medio alto }\end{array}$ & $\begin{array}{l}\text { Existen restricciones de } \\
\text { circulación (diagnosti- } \\
\text { cados COVID(+) activos } \\
\text { o personas en cuaren- } \\
\text { tena preventiva) } \\
\text { Los gobiernos reco- } \\
\text { miendan (no obligan) a } \\
\text { restringir el movimien- } \\
\text { to de población }\end{array}$ & Si & $\begin{array}{l}\text { Inicio luego de } \\
14 \text { días de iniciar } \\
\text { las clases en el } \\
\text { aula } \\
\text { Cumpliendo } \\
\text { protocolos y } \\
\text { recomendaciones } \\
\text { sanitarias }\end{array}$ & $\begin{array}{l}\text { Inicio luego de } \\
14 \text { días de iniciar } \\
\text { las clases. } \\
\text { Cumpliendo } \\
\text { protocolos y } \\
\text { recomendaciones } \\
\text { sanitarias. }\end{array}$ & $\begin{array}{l}\text { Cumpliendo } \\
\text { protocolos, es- } \\
\text { pecífico de cada } \\
\text { Federación } \\
\text { y recomendacio- } \\
\text { nes sanitarias. }\end{array}$ & $\begin{array}{l}\text { Al abrirse los es- } \\
\text { pacios públicos. } \\
\text { Cumpliendo } \\
\text { recomendaciones } \\
\text { sanitarias. }\end{array}$ \\
\hline Fase 3 & $\begin{array}{l}\text { Riesgo } \\
\text { Medio }\end{array}$ & $\begin{array}{l}\text { Existen restricciones de } \\
\text { circulación (diagnosti- } \\
\text { cados COVID(+) activos } \\
\text { o personas en cuaren- } \\
\text { tena preventiva). } \\
\text { Los gobiernos reco- } \\
\text { miendan (no obligan) } \\
\text { evitar aglomeraciones } \\
\text { en la población }\end{array}$ & Si & $\begin{array}{l}\text { Progresión } \\
\text { según protocolo } \\
\text { (tabla 3) y seguir } \\
\text { recomendaciones } \\
\text { sanitarias }\end{array}$ & $\begin{array}{l}\text { Progresión } \\
\text { según protocolo } \\
\text { (tabla 3) y seguir } \\
\text { recomendaciones } \\
\text { sanitarias }\end{array}$ & $\begin{array}{l}\text { Progresión según } \\
\text { protocolo (tabla } \\
\text { 3) específica a } \\
\text { Federación y se- } \\
\text { guir recomenda- } \\
\text { ciones sanitarias }\end{array}$ & $\begin{array}{l}\text { Cumpliendo } \\
\text { recomendaciones } \\
\text { sanitarias. }\end{array}$ \\
\hline Fase 4 & $\begin{array}{l}\text { Riesgo } \\
\text { Bajo }\end{array}$ & $\begin{array}{l}\text { Existen restricciones de } \\
\text { circulación (diagnosti- } \\
\text { cados COVID }(+) \text { activos } \\
\text { o personas en cuaren- } \\
\text { tena preventiva) }\end{array}$ & $\mathrm{Si}$ & $\begin{array}{l}\text { Progresión } \\
\text { según protocolo } \\
\text { (tabla 3) y seguir } \\
\text { recomendaciones } \\
\text { sanitarias }\end{array}$ & $\begin{array}{l}\text { Progresión } \\
\text { según protocolo } \\
\text { (tabla 3) y seguir } \\
\text { recomendaciones } \\
\text { sanitarias }\end{array}$ & $\begin{array}{l}\text { Progresión según } \\
\text { protocolo (tabla } \\
\text { 3) específica a } \\
\text { Federación y se- } \\
\text { guir recomenda- } \\
\text { ciones sanitarias }\end{array}$ & $\begin{array}{l}\text { Cumpliendo } \\
\text { recomendaciones } \\
\text { sanitarias. }\end{array}$ \\
\hline Fase 5 & $\begin{array}{l}\text { Sin restric- } \\
\text { ciones }\end{array}$ & Sin restricciones & Si & Sin restricciones & $\begin{array}{l}\text { Sin restricciones } \\
\text { Competencias }\end{array}$ & $\begin{array}{l}\text { Sin restricciones } \\
\text { Competencias }\end{array}$ & - \\
\hline
\end{tabular}

*Idealmente y dentro que de lo que permite la conectividad, en fases 0 y 1 deberían realizarse clases en línea o a distancia; si no ingresan simultáneamente todos los NNA al aula en fases iniciales, recomendamos también clases en línea a aquellos NNA que se queden en casa.

\section{Parte III: Retorno al Deporte Escolar ${ }^{2,17,20}$}

El deporte escolar es fundamental en el desarrollo integral de los NNA. Les enseña a desenvolverse en deportes individuales y de equipo, a desarrollar técnicas específicas, habilidades sociales, como trabajo en equipo, liderazgo, resiliencia, manejo de la frustración y otros, aprenden a competir, a ganar y también a perder. Debido a la pandemia por COVID-19 se deberán tomar ciertos resguardos al momento de volver con el fin de proteger a los NNA del contagio para evitar que sufran la enfermedad y no sea vectores para la propagación de ella entre familiares y profesores. Con este fin a continuación entregamos una serie de recomendaciones:

Recomendamos el inicio de la AF de los NNA menores de 11 años (4to básico) en clases de Educación Física y Salud en casa y/o AF a nivel familiar, sin contemplar participar de deporte escolar formal cuando la autoridad sanitaria lo determine.

Recomendamos el inicio de los entrenamientos de los NNA entre 11 y 12 años (categoría mini, 5to y 6to básico) a nivel de taller escolares deportivos, sin participar de deporte escolar formal (competencias), cuando la autoridad sanitaria lo determine. 
Tabla 2. Orientaciones generales para el tránsito/retorno a clases de educación física y salud, deporte escolar y universitario para una nueva realidad y desde la perspectiva médico, sanitaria y pedagógica.

\section{Recomendaciones deseables desde la perspectiva médico/sanitaria/pedagógica}

\section{Condiciones minimas antes de la actividad}

En esta fase, se recomienda establecer principios orientadores que promuevan la planificación y los acuerdos institucionales que permitan proyectar de manera óptima el nuevo ethos de la Educación Física, la Salud, el deporte y la recreación en tiempos de pandemia

- Plan de comunicación y Educ. específica

- Se debe cumplir normativa Sanitaria general

- Saludo gestual distanciado positivo y afectivo

- Destacar otros tipos de infecciones respiratorias altas

- Programación y estructura previa de la actividad

- Disponer de implementos para uso individual

- Educación a los deportistas frente a la "nueva realidad"

- Considerar distancias tanto en espacios abiertos como cerrados

- Priorizar objetivos transversales

II. Condiciones mínimas durante la actividad

En esta fase, se desarrolla la puesta en acción de la actividad programada, se intenciona el aprendizaje a partir de estrategias didácticas inclusivas y previamente establecidas y se produce el modelamiento parcial de nuevas conductas en tiempos de pandemia

- Primera etapa realizar actividades pasivas

- Desinfección de mochilas o bolsas al vacío

- Recreos dirigidos evitando juegos con balón

- Debería estar un profesor + ayudante

- Uso de implementos individuales (uso de balones, bastones, etc.)

- Progresar lentamente al ejercicio vigoroso, para evitar alteraciones en la inmunidad que podría generar ejercicio vigoroso de larga duración y de inicio brusco

- Promover ejercicio autónomo dirigido

- Educar la responsabilidad individual
- Disponer de dispensadores con alcohol gel

- Plan de higienización implementos y recintos

- Capacitación de monitores y entrenadores

- Disponer ropa de recambio

- Considerar teoria de la ventana abierta inmunológica con énfasis en la intensidad moderada, según corresponda

- Determinar entrada única y salida diferente para después del ejercicio

- Reforzamiento de educación sanitaria

- Resguardar buena ventilación

- Priorizar el eje de vida activa y saludable que pueden tributar a una mejor condición orgánica
- Inducción personal auxiliar y de gestión

- Capacitación a redes de profesores de educación física

- Higienización de vestuario y de calzado

- Conocer casos de Comorbilidad a través de un cuestionario

- Hidratación con botella de uso personal

- Considerar reintegro progresivo COVID-19

- Generar un screening previo a la educación física y el deporte

- Identificar enfermedades crónicas a través de cuestionario
- Tomar la temperatura a la entrada del recinto

- Controlar entrada al gimnasio/recinto

- Disminuir bloque duración de la clase o actividad

- Evitar contacto con boca, nariz y ojos

- Habilitar basurero y bolsa, y cambiar entre cada actividad

- Demarcación de zonas de seguridad (Espacio delimitado para realizar la actividad y respetar la distancia deportiva)

- No ocupar camarines

- Reforzar medidas de higiene respiratoria
- En una $2^{a}$ etapa realizar act. de moderada intensidad para evitar la inmunosupresión

- Trabajo con grupos pequeños

- Alternancia de materiales entre bloques o turnos

- No realizar actividades que potencien la interacción física

- Disponer de un sector amplio para dejar vestuario

- Promover el autocuidado, cocuidado y la cultura de la prevención primaria

- Resguardar una buena ventilación

III. Condiciones mínimas después la actividad

En esta fase, se produce la vuelta a la calma como también, la verbalización de los aprendizajes significativos, que permiten reforzar actitudes y positivizar conductas en tiempos de pandemia.

- Lavarse manos y cuerpo por grupos

- No utilizar camarines

- Controlar la ansiedad
- Cambiar vestimenta (polera y uso de toalla)

- Procurar controlar su peso corporal

- Generar alimentación balanceada
- Hidratarse con su botella personal e intransferible

- Descansar y tener un buen dormir

- Evitar consumo de alcohol y tabaco

- Dar oportunidad para la autorreflexión postactividad con foco en el autocuidado

*Si bien el objetivo de estas recomendaciones va dirigida principalmente a los NNA (Educación Física y Salud, Deporte Escolar y Federado) esperamos que puedan ser una base para extrapolar al Deporte Universitario. 
Tabla 3. Fases de desescalada o desconfinamiento: Indica la progresión y que indica según nivel de confinamiento, tipo de entrenamiento a realizar (y si contempla uso de implementos), uso de espacios y de camarines.

\begin{tabular}{|c|c|c|c|c|}
\hline Fases & Nivel de confinamiento & $\begin{array}{l}\text { Tipo de entrenamiento } \\
\text { (y uso de implementos) }\end{array}$ & $\begin{array}{l}\text { Uso de espacios e } \\
\text { infraestructura }\end{array}$ & Uso de camarines \\
\hline \multirow[t]{2}{*}{ Fase 0} & \multirow[t]{2}{*}{ Confinamiento Total } & \multirow[t]{2}{*}{$\begin{array}{l}\text { Entrenamiento individual en } \\
\text { casa }\end{array}$} & $\begin{array}{l}\text { Sin acceso agimnasio/cancha/ } \\
\text { club }\end{array}$ & \multirow[t]{2}{*}{ Camarín cerrado } \\
\hline & & & $\begin{array}{l}\text { Sin acceso al uso de dependen- } \\
\text { cias deportivas }\end{array}$ & \\
\hline \multirow[t]{2}{*}{ Fase 1} & \multirow[t]{2}{*}{ Confinamiento parcial } & \multirow{2}{*}{$\begin{array}{l}\text { Entrenamiento individual al } \\
\text { aire libre. En espacios amplios y } \\
\text { poco concurridos, respetando } \\
\text { estrictamente distancias de al } \\
\text { menos } 10 \text { metros }\end{array}$} & $\begin{array}{l}\text { Sin acceso agimnasio/cancha/ } \\
\text { club }\end{array}$ & \multirow[t]{2}{*}{ Camarín cerrado } \\
\hline & & & $\begin{array}{l}\text { Sin acceso al uso de dependen- } \\
\text { cias deportivas }\end{array}$ & \\
\hline \multirow[t]{4}{*}{ Fase 2} & \multirow[t]{4}{*}{$\begin{array}{l}\text { Acceso al recinto deportivo, } \\
\text { con restricción y evaluación } \\
\text { de ingreso* }\end{array}$} & \multirow{3}{*}{$\begin{array}{l}\text { Entrenamiento individual en } \\
\text { recinto deportivo, en campo } \\
\text { abierto o al aire libre, mante- } \\
\text { niendo la distancia deportiva. } \\
\text { Entrenamientos al aire libre en } \\
\text { espacios delimitados. }\end{array}$} & \multirow{4}{*}{$\begin{array}{l}\text { Evitar utilizar espacios peque- } \\
\text { ños como una sala de clases. } \\
\text { Solo permitir uso respetando } \\
\text { la distancia deportiva, con ade- } \\
\text { cuada ventilación y respetando } \\
\text { normas de higiene del material }\end{array}$} & \multirow[t]{2}{*}{$\begin{array}{l}\text { Camarín abierto sólo para } \\
\text { cambio de ropa, sin ducha. } \\
\text { Restricción simultánea de uso } \\
\text { según espacio para personas } \\
\text { que usan transporte público }\end{array}$} \\
\hline & & & & \\
\hline & & & & \multirow{2}{*}{$\begin{array}{l}\text { Limpieza inmediata posterior } \\
\text { al uso }\end{array}$} \\
\hline & & $\begin{array}{l}\text { Uso de implementos solo de } \\
\text { forma individual }\end{array}$ & & \\
\hline \multirow[t]{2}{*}{ Fase 3} & \multirow[t]{2}{*}{$\begin{array}{l}\text { Acceso al recinto deportivo, } \\
\text { con restricción y evaluación } \\
\text { de ingreso* }\end{array}$} & \multirow{2}{*}{$\begin{array}{l}\text { Entrenamiento en grupos } \\
\text { reducidos (máximo } 6 \text { NNA } \\
\text { por sesión, sujeto a espacio } \\
\text { disponible), sin contacto físico } \\
\text { pero con uso de implementos } \\
\text { deportivos (idealmente perso- } \\
\text { nalizados) }\end{array}$} & \multirow[t]{2}{*}{$\begin{array}{l}\text { Evitar utilizar espacios peque- } \\
\text { ños como una sala de clases. } \\
\text { Solo permitir uso respetando } \\
\text { la distancia deportiva, con ade- } \\
\text { cuada ventilación y respetando } \\
\text { normas de higiene del material }\end{array}$} & $\begin{array}{l}\text { Camarín abierto sólo para } \\
\text { cambio de ropa, sin ducha. } \\
\text { Restricción simultánea de uso } \\
\text { según espacio para personas } \\
\text { que usan transporte público }\end{array}$ \\
\hline & & & & $\begin{array}{l}\text { Limpieza inmediata posterior } \\
\text { al uso }\end{array}$ \\
\hline \multirow[t]{4}{*}{ Fase 4} & \multirow[t]{4}{*}{$\begin{array}{l}\text { Acceso al recinto deportivo, } \\
\text { con restricción y evaluación } \\
\text { de ingreso* }\end{array}$} & $\begin{array}{l}\text { Entrenamiento colectivo y } \\
\text { táctico, con interacción entre } \\
\text { deportistas }\end{array}$ & \multirow[t]{4}{*}{$\begin{array}{l}\text { Acceso a utilizar espacios } \\
\text { pequeños respetando el distan- } \\
\text { ciamiento deportivo. Respetar } \\
\text { normas de higiene del material. }\end{array}$} & \multirow{2}{*}{$\begin{array}{l}\text { Camarín abierto sólo para } \\
\text { cambio de ropa, con ducha. } \\
\text { Restricción simultánea de uso } \\
\text { según espacio }\end{array}$} \\
\hline & & \multirow{2}{*}{$\begin{array}{l}\text { Aumento de número de NNA } \\
\text { gradualmente }\end{array}$} & & \\
\hline & & & & \multirow{2}{*}{$\begin{array}{l}\text { Limpieza inmediata posterior } \\
\text { al uso }\end{array}$} \\
\hline & & Partidos de entrenamiento. & & \\
\hline Fase 5 & $\begin{array}{l}\text { Acceso al recinto deportivo, } \\
\text { con evaluación de ingreso* }\end{array}$ & Sin restricción & Sin restricción & Sin restricción \\
\hline
\end{tabular}

*Ver detalles en 'Medidas en Centros de Entrenamiento'.

Recomendamos la realización de entrenamientos y competencias escolares durante este año a mayores de 13 años (categoría infantil y mayores) a nivel local y/o regional cuando la autoridad sanitaria lo determine. Solicitamos privilegiar categorías mayores (intermedia y superior).

Con respecto a las competencias, recomendamos: que se lleven a cabo sin público; que padres y/o tutores sólo deben ir a dejar y a buscar a los NNA y dividir las jornadas por categorías (para evitar aglomeraciones de competidores) No recomendamos las competencias que requieran viajes interregionales debido a motivos logísticos sanitarios.

Recomendamos privilegiar el inicio de los entrenamientos en deportes individuales antes que los de- portes colectivos. Si se decide comenzar a entrenar deportes colectivos, estos deben regirse estrictamente de acuerdo a estos protocolos, enfatizando en la distancia deportiva (tabla 3 ).

\section{Parte IV: Retorno al Deporte Federado en Atletas menores de 20 años Recomendaciones en la progresión para el retorno a los entrenamientos ${ }^{21617}$}

La planificación y progresión específica del entrenamiento (tipo y cargas de trabajo) deberá ser evaluada y realizada por cada federación deportiva, a través de sus cuerpos técnicos, manteniendo en consideración las normas sanitarias expuestas en el documento. 
El Comité Olímpico y Paralímpico considera los 14 años como una edad de inicio para el ámbito federado (categoría Cadetes) en la mayoría de los deportes.

La transición entre las fases será determinada por las autoridades sanitarias nacionales, regionales y comunales; éstas serán las mismas que para el Deporte Escolar mayores a 13 años (tabla 3).

\section{Recomendaciones por grupos etarios y poblaciones especiales}

Menores de 14 años: Debido a la dificultad para obedecer órdenes en forma precisa y a la dependencia familiar para los traslados y acompañamientos, se recomienda que el retorno sea sólo una vez que las autoridades sanitarias lo permitan. Se iniciará el entrenamiento presencial sólo cuando el contexto de la pandemia permita entrenar en Fases 4 a 5 en el caso de deportes colectivos. El entrenamiento en Fase 0-1 debe ser guiado y monitorizado a distancia en forma permanente.

Mayores de 14 años: Sin restricciones específicas, siguiendo medidas sanitarias descritas en tabla 3.

Deporte adaptado/paralímpico: Para los NNA que presente alguna situación de discapacidad motora y/o intelectual, que hayan sido diagnosticados con COVID-19(+), independiente si fueron asintomáticos o sintomáticos, se les solicitará la evaluación y autorización médica, por medio de un certificado médico, previo al reinicio de la AF de intensidad moderada y/o vigorosa.

Los alumnos que sean usuarios de ayudas técnicas (órtesis, carros andadores, bastones y/o silla de ruedas), no deberán suspender su uso si estos generan una mayor estabilidad y/o disminución en el riesgo de caídas y/o accidentes. En el caso de que sus elementos ortopédicos tengan contacto directo con otros alumnos, estos deberán ser desinfectados según la norma sanitaria y/o recomendación de su médico tratante.

En el caso de los alumnos que presenten sialorrea (aumento de la salivación), el establecimiento educacional deberá designar a una persona específica para que asista al alumno en la limpieza, asegurando los elementos de protección personal (EPP) necesarias para esta acción (guantes). En ningún caso se deberá delegar esta acción a un compañero de curso.

\section{Medidas para Atletas y Cuerpo Técnico}

- Lavado de manos con agua y jabón con la técnica correcta por al menos 30 segundos al ingresar y retirarse del complejo deportivo, área médica, comedor y camarines. También podría usarse alcohol gel, pero no reemplaza el lavado de manos y se aconseja usar un máximo de 3 veces entre lavado de manos con agua y jabón.

- No compartir botellas de agua ni artículos personales (incluyendo toallas, ropa, canilleras, etc.).
- No compartir con terceros, bebidas o líquidos, ni alimentos sólidos. La hidratación debe ser individualizada.

- No tener contacto físico directo: esto incluye no realizar saludo de abrazo, de mano o contacto facial.

- Evitar tocarse la cara durante la actividad deportiva.

- Integrantes de Cuerpo Técnico, además de funcionarios deben utilizar mascarilla permanentemente.

- Si presenta tos o estornudos durante entrenamiento cubrirse con el antebrazo, y posteriormente lavarse las manos. No escupir al suelo.

- Evitar reuniones en salones cerrados, promoviendo la actividad al aire libre. Las reuniones que sean imprescindibles se deben realizar en grupos reducidos (menores a 5 personas) y respetando normas sanitarias.

- En caso de presentar algunos de estos síntomas sugerentes de COVID-19: fiebre, tos, pérdida del olfato (anosmia), fatiga desproporcionada, dolor de garganta y/o decaimiento, se recomienda no asistir al centro de entrenamiento y contactarse con el cuerpo técnico y/o médico inmediatamente para tomar las medidas del caso.

- Si algún familiar directo presenta síntomas como los descritos o es caso sospechoso o confirmado de COVID-19, se debe avisar al la brevedad al cuerpo técnico y/o médico para evaluar la situación y definir conductas.

\section{Medidas en Centros y lugares de entrenamiento. Medidas de higiene}

- Se recomienda el uso de pisaderas con solución clorada o amonio cuaternario a la entrada y salida de recintos deportivos

- Limpieza frecuente de superficies deportivas, equipamiento u otros implementos de uso en entrenamientos con soluciones cloradas, amonio cuaternario y/o alcohol gel, de acuerdo con las medidas de higienización dictadas por la norma sanitaria. Debido a que el uso de material e implementos es individual, la limpieza y sanitización del lugar se debe realizar según cada cambio de grupo de entrenamiento y/o atleta que los utilice.

- Para la higienización del lugar entre los diferentes grupos de entrenamiento, debe existir un período de tiempo suficiente para la limpieza y desinfección del lugar y las superficies.

- Los camarines, baños y gimnasios (si se usan) deberán ser higienizados, según protocolo MINSAL (ver pagina 8), previo a los entrenamientos y de los diferentes grupos una vez terminados estos. Así y todo, se recomienda no usar estas instalaciones (excepto baños) en primeras etapas de retorno a 
los entrenamientos, o a su vez priorizar su uso para atletas que utilicen el transporte público como forma de traslado para el cambio de vestimenta.

- Instalación de dispositivos con alcohol gel en áreas de entrenamiento, camarines, gimnasio y otros. Se aconseja usar un máximo de 3 veces entre lavado de manos con agua y jabón.

- Restringir la circulación sólo al personal mínimamente necesario en áreas de entrenamiento, camarines, utilería, gimnasio y otros.

- Se recomienda, que el personal que administra y gestiona los recintos puedan recibir inducciones y capacitación para que de esta forma colaboren en la readecuación a esta nueva realidad.

\section{Medidas de acceso y salida atletas}

- Si el día anterior o el día del entrenamiento algún atleta o miembro del cuerpo técnico presenta algún síntoma respiratorio o es contacto estrecho de caso Covid-19, deberá informar al cuerpo médico y/o cuerpo técnico, permanecer en su casa hasta ser evaluado por el cuerpo médico institución o asistir a su sistema de salud según corresponde. De ningún modo debe concurrir al lugar de entrenamiento con síntomas respiratorios y/o sugerentes de COVID-19.

- El ingreso y egreso deben ser por lugares separados de al menos 2 metros, idealmente completamente separados.

- Registro de quienes ingresan y salen del recinto deportivo, que incluya cuestionario simple de síntomas y contactos y control de temperatura con termómetro infrarrojo (ingreso con temperatura inferior a $37^{\circ} \mathrm{C}$ ). En caso de tener síntomas sugerentes de COVID-19 o haber sido contacto estrecho de caso sospechoso o confirmado, no debe ingresar al recinto deportivo y debe ser reportado al cuerpo médico de la institución o a su sistema de salud, según corresponda.

- Uso de alcohol gel previo a ingreso al entrenamiento.

- Evitar contacto físico en saludos.

- No se permitirá el ingreso de familiares, público, espectadores o personal no autorizados.

\section{Medidas para traslado hacia y desde lugares de entrenamiento.}

- Transporte público:

- Uso obligatorio de mascarilla.

- Ropa de entrenamiento guardada y aislada del ambiente.

- Utilización exclusiva de camarines de institución para cambio de vestimenta.
- Transporte en vehículo particular:

- Evitar paradas en el traslado.

- Si comparten el auto (incluido familiares), el uso de mascarillas es obligatorio.

- Estacionar con distancia de un espacio de estacionamiento. En caso de no haber el espacio necesario para esto, bajarse o subirse al auto en forma escalonada o alternada con el otro deportista del auto, manteniendo siempre la distancia física mínima.

- Traer ropa de entrenamiento puesta y dirigirse directamente al campo de entrenamiento, evitando camarines.

- Bajarse del vehículo y transitar hasta el lugar de entrenamiento con mascarilla.

- Transporte en vehiculos como delegación (buses de traslado):

- Deben respetar espacios y sentarse uno solo por dos asientos

- Al entrar o salir respetar espacio de dos metros

- Mantener mascarillas puestas al subir y bajar y todo el trayecto.

\section{Parte V: Recomendación para Tamizaje Médico-Cardiológico de atletas post COVID-1921-26}

Durante estos meses de infección por COVID-19 y de pandemia, se han observado múltiples manifestaciones clínicas, compromiso de órganos y secuelas de diferentes magnitudes como por ejemplo, pulmonares, cardiológicas (miocarditis, pericarditis e incluso falla cardíaca), musculoesqueléticas, gastrointestinales y hepáticas, por mencionar algunas. Es por esto que recomendamos fuertemente la necesidad que atletas que hayan cursado con COVID-19 sean evaluados por su médico (idealmente especialista en medicina del deporte) para que este otorgue el pase de retorno deportivo o derive oportunamente, acorde a los protocolos publicados.

En Chile, al 04 de junio del 2020, de los 122.495 casos confirmados por COVID-19, alrededor de un $8,0 \%$ son en menores de 18 años. De los menores de 18 años confirmados, alrededor de un 4,2\% están hospitalizados, y de éstos, un 3,7\% están hospitalizados en una Unidad de Paciente Crítico Pediátrico ${ }^{27}$.

Para el ámbito familiar y establecimiento educacional sugerimos las siguientes indicaciones (figura 1):

I. Atleta/alumno con COVID-19 que cursa sin síntomas:

A. Cumplir la cuarentena exigida por la autoridad sanitaria (14 días).

B. Seguimiento de aparición de síntomas y complicaciones. 


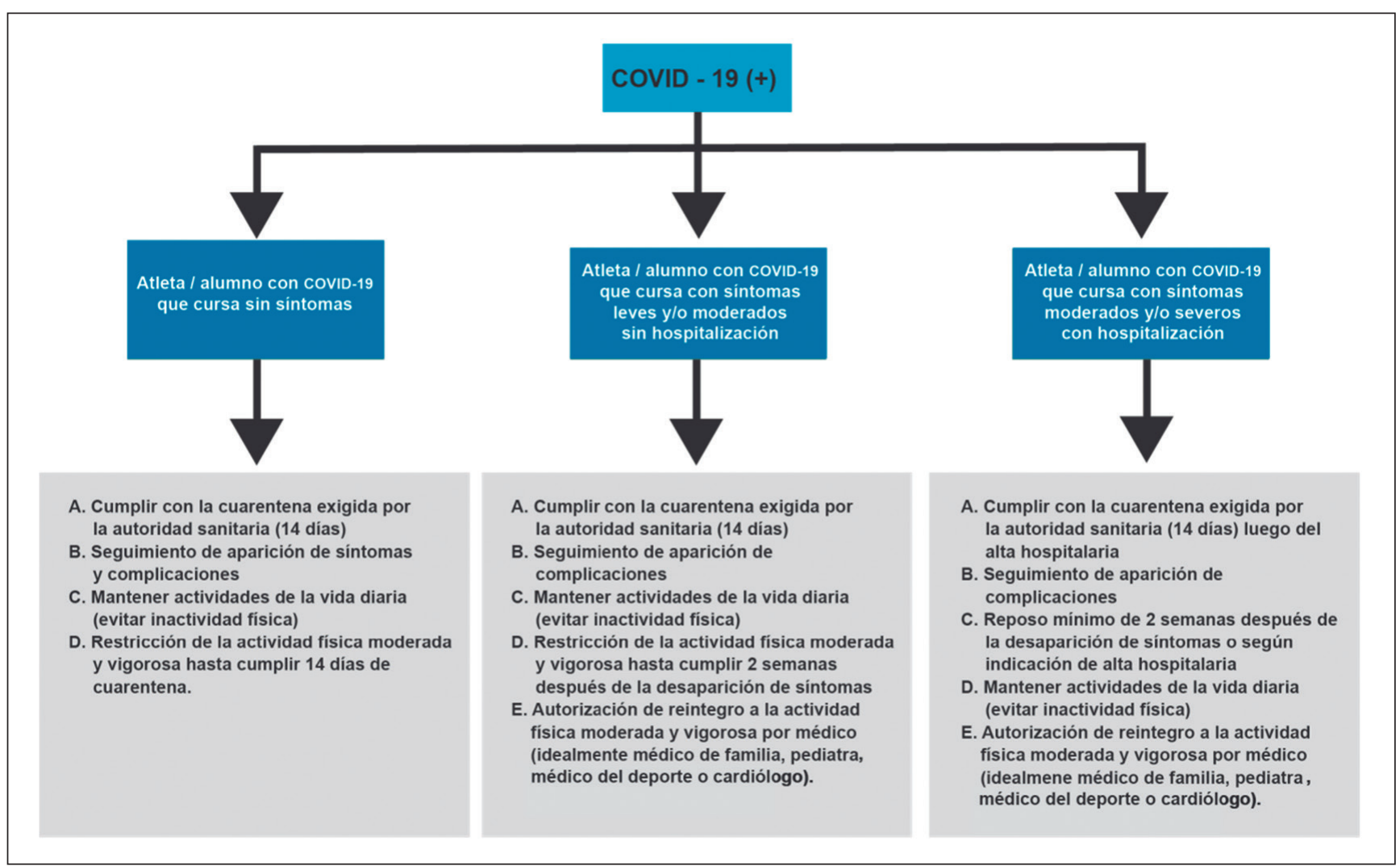

Figura 1. Flujograma de recomendaciones sobre actuación de padres, tutores y profesores para un alumno(a)/atleta que haya sido contagiado por SARS-Cov-2 en sus distintos grados de severidad.

C. Mantener actividades de la vida diaria (evitar inactividad física).

D. Restricción de la actividad física moderada y vigorosa hasta cumplir 14 días de cuarentena.

II. Atleta/alumno con COVID-19 que cursa con síntomas leves y/o moderados sin hospitalización:

A. Cumplir la cuarentena exigida por la autoridad sanitaria (14 días).

B. Seguimiento de aparición de complicaciones.

C. Mantener actividades de la vida diaria (evitar inactividad física).

D. Restricción de la actividad física moderada y vigorosa hasta cumplir 2 semanas después de la desaparición de síntomas.

E. Autorización de reintegro a la actividad física moderada y vigorosa por médico (idealmente médico de familia, médico del deporte, pediatra o cardiólogo pediatra).

III. Atleta/alumno con COVID-19 que cursa con síntomas moderados y/o severos con hospitalización:

A. Cumplir la cuarentena exigida por la autoridad sanitaria (14 días) luego del alta hospitalaria.
B. Seguimiento de aparición de complicaciones.

C. Reposo mínimo de 2 semanas después de la desaparición de síntomas o según indicación de alta hospitalaria.

D. Mantener actividades de la vida diaria (evitar inactividad física).

E. Autorización de reintegro a la actividad física moderada y vigorosa por médico (idealmente médico de familia, médico del deporte, pediatra o cardiólogo pediatra).

Para el ámbito médico, sugerimos el siguiente protocolo, para quienes reciban a la población pediátrica que cursó con COVID-19 (figura 2).

a) Atletas con Test de PCR (+) para COVID-19 y/o con Test de inmunoglobulinas $\mathrm{M} \mathrm{y} \mathrm{G}(+)$ que cursan asintomáticos:

- Historia clínica y examen físico.

- Evaluar electrocardiograma de reposo según criterio.

- Estudio adicional según resultados.

b) Atletas COVID-19 (+) con cuadro clínico leve y control ambulatorio: 


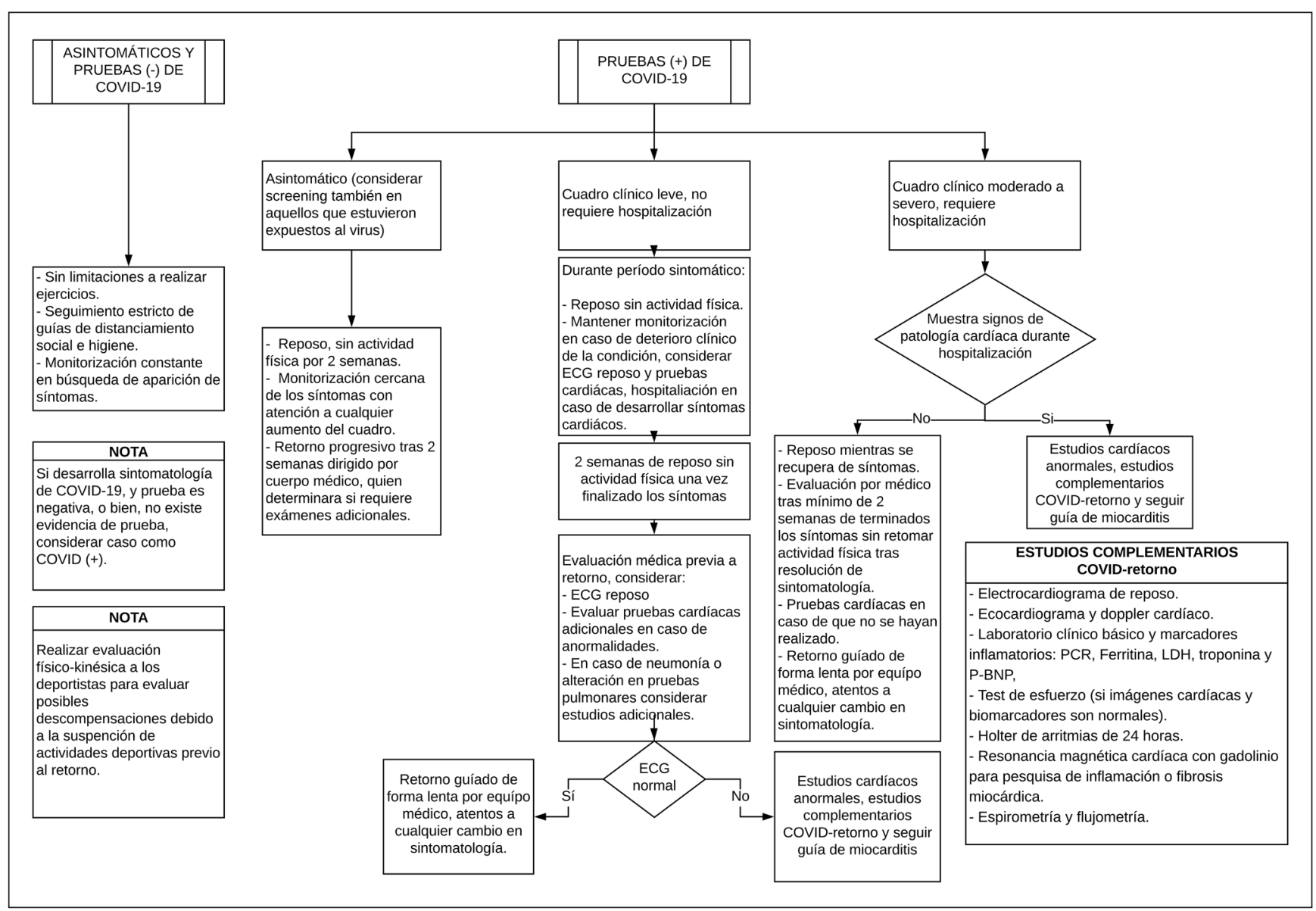

Figura 2. Flujograma para médicos con pacientes NNA que cursan con COVID-19 y el retorno al deporte.

- Historia clínica y examen físico. Evaluar posibles síntomas y signos seculares de sistemas ya mencionados.

- Electrocardiograma de reposo.

- Exámenes adicionales según resultados, si electrocardiograma es anormal o con cambios respecto a previos, debe realizar adicionalmente ecocardiograma y doppler cardíaco y test de esfuerzo y exámenes de laboratorio.

- Si evaluación pulmonar o TAC de tórax estuvo alterado, en particular si hubo sospecha o confirmación de neumonía, esta se debe controlar previo a regresar actividad. Si no hubo estudio debe realizar radiografía de tórax.

c) Deportistas COVID-19 (+) con cuadro clínico moderado a severo (requirió hospitalización).

- Historia clínica y examen físico. Evaluar posibles síntomas y signos secuelares de sistemas ya mencionados.

- Electrocardiograma de reposo.

- Ecocardiograma y doppler cardíaco.
- Test de esfuerzo (si imágenes cardíacas son normales).

- Laboratorio clínico con marcadores inflamatorios: PCR, Ferritina, $\mathrm{LDH}$, troponina y P-BNP

- Si hubo sospecha o confirmación de neumonía, esta se debe controlar previo a regresar actividad. Si no hubo estudio debe realizar al menos radiografía de tórax y espirometría (flujometría).

- Evaluación física-kinésica previo a reintegro deportivo, evaluando pérdida de masa muscular y fuerza.

d) Atletas COVID-19 (+) con demostración de compromiso cardíaco durante su hospitalización independiente de su gravedad clínica o Sospecha o diagnóstico de miocarditis o compromiso por sepsis o "tormenta de citoquinas" y/o ventilación mecánica:

- Historia clínica y examen físico. Evaluar posibles síntomas y signos secuelares de sistemas ya mencionados. 


\section{Tabla 4. Resumen de recomendaciones}

- Evitar la inactividad física durante el confinamiento. Estimular a través de clases guiadas o planes de entrenamiento a sus alumnos/atletas

- Los NNA deben practicar AF moderada a intensa por 60 minutos al dia (OMS)

- Al retorno, volver en forma progresiva en volumen e intensidad a la AF o entrenamientos con el fin de evitar lesiones

- No usar mascarillas durante la AF o entrenamiento; sin embargo tener una o varias en la cercanía para usarla antes o después

- Al realizar AF con otros considerar la distancia deportiva, 5 metros del otro al realizar AF moderada y $10 \mathrm{~m}$ o más en AF más intensa. Tener esto en cuenta al planificar clases o entrenamiento

- Comenzar la AF o entrenamiento individualmente, luego en grupos pequeños y cada vez mayores conforme pasen las semanas, respetando la distancia deportiva

- Uso de espacios desde ser en relación a lo que permita la distancia deportiva, más que si son abiertos o cerrados

- Respetar y estimular el cumplimiento de las normas sanitarias. Incorporar la enseñanza de éstas en clases de EFyS

- Progresar en contacto físico, uso de infraestructuras, intensidad de ejercicio según fases de progresión o desescalada según realidad epidemiológica local y nacional (tabla 3)

Recomendaciones en deporte escolar:

- Recomendamos el inicio de la AF de los NNA menores de 11 años (4to básico) en clases de Educación Física y Salud en casa y/o AF a nivel familiar, sin contemplar participar de deporte escolar formal cuando la autoridad sanitaria lo determine.

- Recomendamos el inicio de los entrenamientos de los NNA entre 11 y 12 años (categoría mini, 5to y 6to básico) a nivel de taller escolares deportivos, sin participar de deporte escolar formal (competencias), cuando la autoridad sanitaria lo determine

- Recomendamos la realización de entrenamientos y competencias escolares durante este año a mayores de 13 años (categoría infantil y mayores) a nivel local y/o regional cuando la autoridad sanitaria lo determine. Solicitamos privilegiar categorías mayores (intermedia y superior).

- Con respecto a las competencias, recomendamos: que se lleven a cabo sin público; que padres y/o tutores sólo deben ir a dejar y a buscar a los NNA y dividir las jornadas por categorías (para evitar aglomeraciones de competidores) No recomendamos las competencias que requieran viajes interregionales debido a motivos logísticos sanitarios.

- Recomendamos privilegiar el inicio de los entrenamientos en deportes individuales antes que los deportes colectivos. Si se decide comenzar a entrenar deportes colectivos, estos deben regirse estrictamente de acuerdo a estos protocolos, enfatizando en la distancia deportiva.

Recomendaciones en deporte federado:

- La planificación y progresión específica del entrenamiento (tipo y cargas de trabajo) deberá ser evaluada y realizada por cada federación deportiva, a través de sus cuerpos técnicos, manteniendo en consideración las normas sanitarias expuestas en el documento.

- Desde los 14 años, la transición entre las fases será determinada por las autoridades sanitarias nacionales, regionales y comunales; éstas serán las mismas que para el Deporte Escolar mayores a 13 años (ver Tabla 3).

Recomendaciones en Grupos etarios y poblaciones especiales

- Menores de 14 años: Debido a la dificultad para obedecer órdenes en forma precisa y a la dependencia familiar para los traslados y acompañamientos, se recomienda que el retorno sea sólo una vez que las autoridades sanitarias lo permitan. Se iniciará el entrenamiento presencial sólo cuando el contexto de la pandemia permita entrenar en Fases 4 a 5 en el caso de deportes colectivos. El entrenamiento en Fase 0-1 debe ser guiado y monitorizado a distancia en forma permanente.

- Deporte adaptado/paralímpico: Para los NNA que presente alguna situación de discapacidad motora y/o intelectual, que hayan sido diagnosticados con COVID-19(+), independiente si fueron asintomáticos o sintomáticos, se les solicitará la evaluación y autorización médica, por medio de un certificado médico, previo al reinicio de la AF de intensidad moderada y/o vigorosa.

Los alumnos que sean usuarios de ayudas técnicas (órtesis, carros andadores, bastones y/o silla de ruedas), no deberán suspender su uso si estos generan una mayor estabilidad y/o disminución en el riesgo de caídas y/o accidentes. En el caso de que sus elementos ortopédicos tengan contacto directo con otros alumnos, estos deberán ser desinfectados según la norma sanitaria y/o recomendación de su médico tratante. En el caso de los alumnos que presenten sialorrea (aumento de la salivación), el establecimiento educacional deberá designar a una persona específica para que asista al alumno en la limpieza, asegurando los elementos de protección personal (EPP) necesarias para esta acción (guantes). En ningún caso se deberá delegar esta acción a un compañero de curso

- NNA con enfermedades crónicas: Los NNA atletas que padezcan enfermedades crónicas ya sean cardiológicas, pulmonares, endocrinológicas, neurológicas, inmunológicas u otras, deben ser evaluados por su médico tratante, independiente de la fase de progresión o el estatus de contagio, previo a reintegrarse a los entrenamientos. De esta manera se evaluará, en forma individual, el estado clínico del NNA, la progresión de la carga, los cuidados o 'banderas rojas' para el paciente, su familia y el entrenador junto con el riesgo de un potencial contagio con COVID-19

- Las normas sanitarias establecidas para los atletas y cuerpo técnico deben ser seguidas rigurosamente para prevenir contagios

- Las normas en los lugares de entrenamiento contemplan medidas de higiene durante los entrenamientos y entre éstos, controles y distancia en los accesos y salidas y medidas para el traslado.

- Los NNA que hayan tenido COVID-19 pero no hayan tenido síntomas podrán realizar AF sin autorización médica después de 14 días desde la positividad de PCR pero con alto grado de observación por síntomas (figura 2)

- Los NNA que hayan tenido COVID-19 y hayan sido sintomáticos deberán ser autorizados por médico para realizar AF según figura 2

- Debido al riesgo de complicaciones cardíacas y pulmonares por COVID-19 los médicos podrán la propuesta de manejo seguir el flujograma en figura 2 
- Electrocardiograma de reposo.

- Ecocardiograma y doppler cardíaco.

- Laboratorio clínico básico y marcadores inflamatorios: PCR, Ferritina, LDH, troponina y P-BNP.

- Test de esfuerzo (si imágenes cardíacas y biomarcadores son normales).

- Holter de arritmias de 24 horas.

- Resonancia magnética cardíaca con gadolinio para pesquisa de inflamación o fibrosis mio- cárdica.

- Si hubo sospecha o confirmación de neumonía, esta se debe controlar previo a regresar actividad. Si no hubo estudio debe realizar al menos radiografía de tórax y espirometría (flujometría).

- Evaluación física-kinésica mandatoria previo a reintegro deportivo, evaluando pérdida de masa muscular y fuerza (tabla 4).

\section{Referencias}

1. Kamps BS, Hoffmann C. Covid Reference Edición 2020-1. www.covidreference.com. Uploaded 7 de abril de 2020. Accedido 10 de mayo de 2020.

2. Yáñez F, Radice F, Moran M, et al. Propuesta de protocolo para regreso a la actividad deportiva en el fútbol. Documento oficial de la Comisión Médica de ANFP. (2020) http://anfpfotos.cl/ notas/Propuesta_Protocolo_ANFP_ Abril_2020_2.pdf.

3. Mujika I, Padilla S. Detraining: Loss of Training-Induced Physiological and Performance Adaptations. Part I. Sports Med 30, 79-87. (2000) https://doi. org/10.2165/00007256-200030020-00002.

4. Blair SN. Physical inactivity: the biggest public health problem of the 21st century British Journal of Sports Medicine 2009;43:1-2.

5. Kohl HW, Craig CL, Lambert EV, et al. The pandemic of physical inactivity: global action for public health. The Lancet (2012)380;9838:294-305.

6. Pillaya $L$, Janse van Rensburga D, Jansen van Rensburga A, et al. Nowhere to hide: The significant impact of coronavirus disease 2019(COVID-19) measures on elite and semi-elite South African athletes. 2020. https://doi.org/10.1016/j. jsams.2020.05.016.

7. Myer G, Faigenbaum A, Cherny C, Heidt, R Hewett T. Did the NFL Lockout Expose the Achilles Heel of Competitive Sports? Journal of Orthopaedic \& Sports Physical Therapy. 2011;41;10:702-5.

8. Sarto F, Impellizzeri FM, Spörri J, et al. Impact of potential physiological changes due to COVID-19 home confinement on athlete health protection in elite sports: a call for awareness in sports programming. 2020. Retrieved from osf.io/preprints/ sportrxiv/4zb3a.

9. Andreato L, Danilo R. Coimbra D, Alexandro Andrade A. Challenges to Athletes During the Home Confinement Caused by the COVID-19 Pandemic. Strength and Conditioning Journal. 2020 (42)3. https://dx.doi.org/10.1519\%2FS
SC.0000000000000563.

10. Casais-Martínez, L, Sanroman-Cortés, Z, Del Hoyo-Lora, M, Solla-Aguiar, J, Lago-Peñas, C. Return to training and competition after COVID-19 in professional football. Science Performance and Science Reports.2020.102;1.

11. Mason J. May 20 The Bundesliga Blueprint: early lessons from the return of German football. May 25 The Bundesliga Blueprint: the snapshot becomes a story. https://www.trackademicblog.com/blog/ thesnapshotbecomesastory. Accedido 30 mayo de 2020.

12. Davis BA, Tsen LC. Wearing an N95 Respiratory Mask: An Unintended Exercise Benefit?. Anesthesiology. 2020. Advance online publication. https://doi org/10.1097/ALN.0000000000003421.

13. Pifarre F, Dulanto D, Grazioli G, de Yzaguirre I, Maura I. COVID-19 and masks in sports. Apunts Sports Medicine. doi.org/10.1016/j. apunsm.2020.06.002.

14. Blocken B, Malizia F, van Druenen T, Marchal T. Towards aerodynamically equivalent COVID-19 $1.5 \mathrm{~m}$ social distancing for walking and running; 2020: 1-12.Available at: urbanphysics.net. Accedido 30 de mayo, 2020.

15. Centers for Disease Control and Prevention. Coronavirus Disease 2019 (COvid-19). Healthy Swimming. https:// www.cdc.gov/healthywater/swimming/ index.html. Accedido 3 de junio de 2020.

16. Centers for Disease Control and Prevention. Coronavirus Disease 2019 (COvid-19) Considerations for Youth Sports. Centers for disease Control and Prevention. (2020) https://www.cdc.gov/ coronavirus/2019-ncov/community/ schools-childcare/youth-sports.html. Accedido 3 de junio de 2020.

17. Chen P, Mao L, Nassis GP, Harmer P, Ainsworth BE, Li F. Returning Chinese school-aged children and adolescents to physical activity in the wake of COVID-19: Actions and precautions. Journal of sport and health science, 00 (2020) 13. https://doi.org/10.1016/j. jshs.2020.04.003.

18. Organización Mundial de la Salud.
Estrategia Mundial sobre regimen alimenticio, actividad física y salud. Actividad Física en los jóvenes. https:// www.who.int/dietphysicalactivity/ factsheet_young_people/es/. Accedido 2 de junio de 2020.

19. Falvey É, Mathema P, Horgan M, Raftery M. Retorno seguro al rugby en el contexto de la pandemia COVID-19. 27 abril 2020. World rugby. Player Welfare Putting players first. Recuperado de https://playerwelfare.worldrugby. org/?documentid=219.

20. Hughes D, Saw R, Panagodage N, et al. The Australian Institute of Sport (AIS) Framework for rebooting sport in a covid-19 environment. Journal of Science and Medicine in Sport. (2020) https://doi. org/10.1016/j.jsams.2020.05.004

21. Marqueta PM, Bonafonte LF. Reconocimientos médicos para la aptitud deportiva. Documento de consenso de la Sociedad Española de Medicina del Deporte (SEMED-FEMEDE). Archivos de medicina del deporte: revista de la Federación Española de Medicina del Deporte y de la Confederación Iberoamericana de Medicina del Deporte 2017;34(1):10-30.

22. Yáñez F, Radice F, Moran M, et al. Evaluacion cardiológica previo al regreso a entrenamientos en deportistas que presentaron COVID-19. (2020). Documento oficial Comisión Médica ANFP. Asociación Nacional de Fútbol Profesional. Chile. http://www.anfp.cl/ noticia/35362/anfp-y-clubes-participanen-nueva-reunion-de-la-comision-deretorno- del-futbol.

23. Bhatia R, Marwaha S, Malhotra A, et al. Exercise in the Severe Acute Respiratory Syndrome Coronavirus-2 (SARSCoV-2) era: A Question and Answer session with the experts Endorsed by the section of Sports Cardiology \& Exercise of the European Association of Preventive Cardiology (EAPC). European Journal of Preventive Cardiology 2020;0(0):1-10. https://doi. org/10.1177\%2F2047487320930596.

24. Schellhorn P, Klingel K, Burgstahler C. Return to sports after COVID-19 
infection. Do we have to worry about myocarditis?. European Heart Journal. 2020;0:1-3 https://doi.org/10.1093/ eurheartj/ehaa448.

25. Hull J, Loosemore M, Schwellnus M. Respiratory health in athletes: facing the COVID-19 challenge. Lancet Respir
Med 2020 Published Online April 8, 2020 https://doi.org/10.1016/S22132600(20)30175- 2.

26. Barker-Davies RM, O’Sullivan O, Senaratne KPP, et al. The Stanford Hall consensus statement for post-COVID-19 rehabilitation. British Journal of Sports
Medicine, bjsports-2020-102596. (2020). doi: 10.1136/bjsports-2020-102596.

27. Informe Epidemiológico No 23 . Enfermedad por SARS-CoV-2 (COVID-19). Chile 05-06-2020. Informe Rama de Intensivo Pediátrico - SOCHIPE COVID 19. Chile 05-06-2020. 